\title{
Los Derechos de las Víctimas en la Ley 906 de 2004. Análisis de la dinámica procesal en la investigación de delitos sexuales contra mujeres
}

\author{
María Isabel Afanador Contreras \\ Especialista en Derecho Penal de la Universidad Autónoma de Bucaramanga. Especialista en Docencia Universitaria \\ de la Universidad Industrial de Santander-UIS. Abogada de la Universidad Externado de Colombia. Profesora \\ Asociada de la Escuela de Derecho y Ciencia Politica Universidad Industrial de Santander. Integrante Grupos de \\ investigación Derecho y Sociedad; e Historia, Archivística. \\ E-mail: afanador@uis.edu.co
}

\begin{abstract}
Resumen
Este artículo es resultado de la investigación alrededor de los derechos de las mujeres víctimas de delitos sexuales en la ciudad de Bucaramanga, en el ámbito del proceso penal con tendencia acusatoria previsto en la Ley 906 de 2004, en el cual se analiza desde la perspectiva de género, si la población femenina que se tuvo como muestra para el estudio cuenta con un efectivo acceso a la justicia en la etapa de investigación, y sea compatible con los instrumentos internacionales de derechos humanos que prohíben toda forma de discriminación y violencia contra la mujer.
\end{abstract}

Palabras clave: Género, Delitos Sexuales, Víctimas, Proceso Penal.

\begin{abstract}
This reflection paper is the result of research about the rights of women victims of sexual crimes in the city of Bucaramanga, in the field of criminal process with accusatory, expected in the Law 906 of 2004, which is analyzed for the female gender considering if the population for this study, has effective access to justice in the investigation stage, compatible with international human rights instruments prohibiting all forms of discrimination and violence against woman.
\end{abstract}

Keywords: Gender, Sexual Offenses, Victims, Criminal Proceedings.

\section{Résumé}

Ce document de réflexion est le résultat de la recherche sur les droits des femmes victimes de crimes sexuels dans la ville de Bucaramanga, dans le cadre d'une procédure pénale dispositions tendances accusatrices de la loi 906 de 2004, qui est analysé à partir de la genre si la population féminine qui a été échantillonné pour l'étude, l'accès effectif à la justice dans la phase d'enquête, qui est compatible avec les instruments internationaux des droits de l'homme interdisant toutes les formes de discrimination et de violence contre les femme.

Mots-clés: Sexe, Infractions Sexuelles, Les Victimes, Les Poursuites Pénales 



\section{Los Derechos de las Víctimas en la Ley 906 de 2004. Análisis de la dinámica procesal en la investigación de delitos sexuales contra mujeres*}

María Isabel Afanador Contreras

\section{INTRODUCCIÓN}

El estudio que se presenta parte de una mirada incluyente de la mujer en la sociedad como sujeto de derechos, deberes y responsabilidades en igualdad de condiciones con el hombre. Sin embargo, la historia da cuenta de un conjunto de actitudes sociales que construidas desde lo cultural y político, apuntan a la discriminación contra la mujer si se tienen en cuenta los roles diferenciados atribuidos en función de la superioridad masculina. Todo ello en menoscabo de la autonomía de la mujer y la consiguiente violación de sus derechos en escenarios incesantes de violencia, en donde la violencia sexual también permanece.

Es de resaltar que si bien el artículo se aborda desde la perspectiva de género como categoría de análisis, no descarta la existencia de posiciones diversas que a partir de enfoques socioculturales intentan explicar otros orígenes al fenómeno de la violencia sexual más allá del sometimiento de los sujetos, con apoyo en los significados atribuidos al cuerpo, pero que en todo caso se asocian de manera transversal a la problemática bajo estudio. Para Muñiz (2011) "las sociedades actuales conciben a los sujetos como entes escindidos, separados de sus cuerpos; desde esta mirada el cuerpo es lo contingente del sujeto, lo prescindible" (p. 87).

Según expresa Torras (2007):

Existe un reconocimiento ligado a una modelación y disciplinamiento sobre los cuerpos y sus actuaciones sociales, que los esculpe y los jerarquiza en función de un cuerpo ideal para cada identidad establecida: hombre, mujer, rico, pobre, blanco, negro [...] El cuerpo es fronterizo, se relaciona bidireccionalmente con el entorno sociocultural; lo constituye pero a la vez es constituido por él (p.21).

Lo planteado hasta ahora resulta acorde con lo dicho por Carmona (2010) "el sistema sexo-género es una simbolización cultural construida a partir de la diferencia sexual que rige el orden humano y se manifiesta en la vida social, política y económica" (p.11). Por ello, la reproducción de un imaginario social sexista y excluyente desvela-a

* Artículo de la investigación ya finalizada: "Los derechos y las garantías de la mujer víctima de violencia sexual en Bucaramanga, bajo la vigencia de la Ley 906 de 2004”. El proyecto se inició el 1 de febrero 2011 y concluyó el 31 d e enero de 2012. Código 5243 Vicerrectoría de Investigación y Extensión de la Universidad Industrial de Santander-UIS. Bucaramanga. Financiación UIS. 
lo largo de siglos de historia -la existencia de patrones culturales subyacentes a las relaciones de género, que no sólo ubican a la mujer en situación de desigualdad y vulnerabilidad, sino a su vez, la exponen a ser objetivo de victimización sexual.

En torno a estos aspectos, Pitch (2003) sostiene que:

La violencia sexual tiene su propia historia, tanto en el sentido de que lo que se percibe y define como tal, en el tiempo y en las diferentes culturas y sociedades, como en el sentido, interrelacionado, de que cambien las funciones que se le pueden atribuir, el uso simbólico y político que se hace de ella, las representaciones de las relaciones entre los sexos, clases, etnias, pueblos en que pueda producirse (p. 200).

Conviene recalcar que la violencia de género, en particular la violencia sexual contra la mujer, constituye una violación de derechos humanos según se ha reconocido en distintos instrumentos internacionales.

En el ámbito nacional, el estudio abarca el aspecto legal y varios desarrollos de la jurisprudencia constitucional en materia de los derechos de las víctimas en el proceso penal colombiano. A nivel local, incluye un análisis del procesamiento de las denuncias interpuestas ante las Fiscalías adscritas al Centro de Atención Integral de Víctimas de Abuso Sexual ${ }^{1}$, por delitos sexuales contra mujeres mayores de edad en el período que comprende los años 2007 a 2010.

Si bien se ha discutido públicamente la problemática de violencia sexual contra las mujeres, los trabajos realizados hasta el momento en la región, tan sólo muestran mediante estadísticas dispersas el número de casos denunciados, sin que se realice un análisis desde la perspectiva de los derechos humanos y de la dinámica procesal propia del sistema de justicia penal vigente que permita visibilizar la dimensión del fenómeno.

\section{CARACTERIZACIÓN DE LA VÍCTIMA EN EL PROCESO PENAL DE LA LEY 906 DE 2004}

Caracterizar la víctima implica varias cosas. La primera de ellas, precisar su concepto a fin de determinar los presupuestos exigibles por la legislación para adquirir esa condición frente al sistema penal. La segunda, hace relación a los derechos que por normas internas e internacionales le son reconocidos.

En efecto, a nivel interno la Ley 906 de 2004 en su artículo 132 entiende por víctimas a "las personas naturales o jurídicas y demás sujetos de derechos que individual o colectivamente hayan sufrido algún daño como consecuencia del injusto". Este concepto deja entrever, de un lado, una tendencia restringida en cuanto limita la causa de la victimización exclusivamente al delito, y del otro, indica el lugar significativo que ocupa la ocurrencia del daño irrogado como criterio que viabiliza la

1 En adelante CAIVAS-Bucaramanga. 
acreditación procesal de la víctima, aspecto que resulta compatible con la tendencia del derecho internacional, de determinar la condición de víctima desde el daño sufrido como consecuencia del crimen.

En el ámbito internacional sobresale la Declaración sobre los Principios Fundamentales de Justicia para las Víctimas de Delitos y Abuso de Poder (ONU-1985), al definir a las víctimas desde una visión omnicomprensiva, independientemente de cuál sea el origen de la victimización, a diferencia de lo dispuesto en la ley nacional. La precitada Declaración, determina como víctimas a aquellas personas que individual o colectivamente hayan sufrido daños, incluidos lesiones físicas o mentales, sufrimiento emocional, pérdida financiera o menoscabo sustancial de sus derechos fundamentales, como consecuencia de acciones u omisiones que violen la legislación penal vigente en los Estados Miembros, incluida la que proscribe el abuso del poder.

Por su parte, la Recomendación (85) 11, adoptada por el Comité de Ministros del Consejo de Europa(1985), se ocupa de la posición de la víctima en el marco del derecho penal y del proceso penal al considerar que: "Hay que tener además en cuenta, a estos fines, en el sistema de justicia penal, los perjuicios físicos, psicológicos, materiales y sociales sufridos por las víctimas" y sugiere a los gobiernos revisar su legislación y su práctica de conformidad con unas directrices aplicables en diversos niveles a fin de garantizar los derechos de las víctimas².

Ahora bien, la participación de la víctima en el proceso penal con tendencia acusatoria vigente en Colombia, tropieza con limitaciones de orden estructural, derivadas del sistema definido por la Carta Política en su artículo 250 (modificado por el Acto Legislativo No. 03 de 2002, Art. 2), el cual no sólo atribuye a la Fiscalía General de la Nación la función de persecución penal, sino a la par, la de velar por la protección de las víctimas, condicionando el carácter de su intervención a los dictados del legislador.

Ahora, importa destacar que el estatuto procesal penal vigente (Ley 906 de 2004) asume a la víctima como interviniente especial, esto es, exceptuada de varias de las facultades intrínsecas al rol de parte, puesto que si se convierte en acusador adicional y distinto al Fiscal, generaría tanto desigualdad de armas, como una transformación esencial de los rasgos propios de un sistema adversarial en la etapa del juicio. Incluso, la jurisprudencia constitucional enfatiza que la ley citada no le resta a la víctima del delito sus derechos a la verdad, la justicia y la reparación integral, así no tenga la calidad de parte.

De este tema se ha ocupado en varias oportunidades la Corte Constitucional $^{3}$ a fin de precisar, por una parte, la caracterización de la víctima como interviniente

2 Recuperado el 14 de marzo de 2013, de http://www.victimas.org/html/internacional/ legislacioneuropea.pdf

3 Al respecto, puede consultarse la Sentencia C-454/2006, M.P.: Jaime Córdoba Triviño, corregida mediante Auto 248 del mismo año. 
especial no supeditada al fiscal ${ }^{4}$, y por la otra, armonizar el ejercicio de sus derechos de acuerdo con las características singulares del sistema procesal previsto en la Constitución ${ }^{5}$. En sentido análogo, la Sentencia C-260 de 2011 del mismo tribunal, resulta explicativa del asunto en análisis, puesto que determina el alcance de los derechos de las víctimas en la etapa del juicio, cuando explica cómo la naturaleza adversarial, especialmente notoria en la etapa del juicio, reduce significativamente su facultad de participación directa, pues su intervención alteraría los rasgos estructurales del sistema penal y por esa vía menoscabaría otros derechos o principios como el de igualdad de armas. No obstante, la víctima a través de su abogado, podrá ejercer sus derechos en la etapa del juicio sin convertirse en una parte que pueda presentar y defender su propio caso al margen del Fiscal. El conducto para culminar en esta etapa final del proceso el ejercicio de sus derechos es el fiscal, quien debe oír al abogado de la víctima. Así, por ejemplo, éste podrá aportar a la Fiscalía observaciones para facilitar la contradicción de los elementos probatorios, antes y durante el juicio oral, pero sólo el fiscal tendrá voz en la audiencia. En el evento de que la víctima y su abogado estén en desacuerdo con la sentencia podrán ejercer el derecho de impugnarla, de conformidad con el artículo 177 de la Ley 906 de 2004. Así, el derecho de intervención de las víctimas no se ve drásticamente afectado puesto que pueden canalizar su derecho de intervención en el juicio no solamente a través de una vocería conjunta, sino mediante la intervención del propio Fiscal, tal como lo ha señalado la Corte en anteriores oportunidades, refiriéndose al aspecto probatorio y de argumentación que la exclusión de su participación en el juicio no constituye una vulneración de sus derechos.

Sin duda, la Corte Constitucional reconoce las limitaciones ${ }^{6}$ de la participación directa de la víctima en el juicio oral presentando pruebas e interrogando o contrainterrogando testigos, por cuanto como ya se indicó, quebranta el principio de igualdad de armas, propio de un sistema acusatorio, como lo aduce en la Sentencia C-209 de 2007, y deja en manos del apoderado el ejercicio de los derechos en la etapa del juicio, claro está, sin que pueda constituirse en parte procesal independiente y autónoma, pues su actuación debe ir de la mano del fiscal del caso, empero, la misma

4 Ya en la Sentencia C-209/ 2007, M.P.: Manuel José Cepeda Espinosa, se afirma por la Corte Constitucional que la víctima del delito no es un sujeto pasivo de protección por parte de la Fiscalía sino un interviniente activo, constitucionalmente legitimado para hacer valer sus derechos dentro del proceso penal instaurado por el Acto Legislativo 03 de 2002 y la Ley 906 de 2004. En el mismo pronunciamiento, se ratifica la titularidad de la acción penal en el Fiscal, quien en ejercicio de dicha acción se encarga no solo de representar los intereses del Estado, sino a la vez, de promover los intereses de las víctimas. Sin embargo, ello no implica en el sistema colombiano que las víctimas carezcan de derechos de participación en el proceso penal. Estas pueden actuar sin sustituir ni desplazar al Fiscal.

5 En esta dirección, la Sentencia C-250 de 2011, con ponencia del Magistrado Mauricio González Cuervo.

6 En efecto, por vía jurisprudencial se ha dilucidado que los elementos definitorios de la participación de la víctima como interviniente especial en las distintas etapas del proceso penal, depende de aquella en que se encuentre, de allí que la posibilidad de intervención directa es mayor en las etapas previas y posteriores al juicio. 
Corte $^{7}$ menciona que la exclusión de su participación en el juicio no constituye una vulneración de sus derechos.

No puede dejarse a un lado, como a diferencia de la Ley 906 de 2004, en la Ley 600 de 2000 -bajo un esquema de proceso distinto al actual- la intervención de la víctima se concretaba en la constitución de parte civil con facultades para solicitar la práctica de pruebas en cualquier momento de la actuación, aspecto que conllevó a una notable garantía para el ejercicio de sus derechos. Tal como lo afirma Patiño (2009) "difícilmente se encontrará una mayor posibilidad de participación procesal en ordenamiento jurídico procesal alguno que aquella que tiene en el régimen de la Ley 600/00" (p.15). Ya en la Sentencia C-228 de 2002, la Corte Constitucional, otorga a la víctima plenas facultades de parte procesal, no circunscritas al factor civil.

Como se sabe, el Acto Legislativo No. 6 de Noviembre 24 de 2011, reformó de nuevo el artículo 250 de la Constitución Política con la adición de un parágrafo que permite al Congreso -atendiendo la naturaleza del bien jurídico y la menor lesividad de la conducta punible- asignarle el ejercicio de la acción penal a la víctima o a otras autoridades distintas a la Fiscalía General de la Nación, que podrá actuar en forma preferente. La inclusión de la figura del acusador particular procederá para los delitos que fije el legislador. Con ello se busca desmonopolizar el ejercicio de la acción penal, en el intento de evitar el colapso del sistema penal acusatorio, disminuir la impunidad y de paso impedir que las víctimas se sometan a la congestión judicial, como se aduce en la exposición de motivos ${ }^{8}$.

\section{LOS DERECHOS DE LAS VÍCTIMAS EN LA LEY 906 DE 2004}

De cara a los desarrollos del derecho internacional, se ha ampliado el contenido de los derechos de las víctimas, pues su protección no sería adecuada de contraerse a la simple indemnización de perjuicios. De allí surge el deber estatal de garantizar el derecho de acceso a la administración de justicia a través de un recurso judicial efectivo que posibilite, tanto la reparación del daño irrogado a partir de la conducta, como el derecho a conocer la verdad de lo ocurrido, con miras a la sanción de los responsables.

7 Para profundizar este aspecto consultar la Sentencia C- 260/2011.

8 La exposición de motivos del Acto Legislativo 6 de 2011, menciona entre algunas de las justificaciones para introducir la figura del acusador particular cómo "Cientos de miles de procesos se encuentran actualmente en etapa de indagación sin que la Fiscalía General de la Nación cuente con la infraestructura suficiente para tomar una decisión de fondo sobre su archivo o sobre la necesidad de realizar una formulación de imputación que impulse el proceso, lo cual en la actualidad genera una profunda incertidumbre en las víctimas y que en muy poco tiempo producirá la inminente prescripción de muchos de los delitos denunciados, creando una situación insostenible de impunidad y una crisis muy grave de la justicia penal en Colombia”. Recuperado Junio 15 de 2012, http//:www.secretariasenado.gov.co 
Alrededor de la tutela judicial efectiva, la Declaración Universal de Derechos Humanos (ONU, 1948) establece el derecho de toda persona a un recurso efectivo ante los tribunales nacionales competentes, que la ampare contra actos que violen sus derechos fundamentales reconocidos por la constitución o por la ley. En la misma dirección, la Declaración Americana de los Derechos y Deberes del Hombre (OEA, 1948) estatuye que toda persona puede ocurrir a los tribunales para hacer valer sus derechos. Asimismo debe disponer de un procedimiento sencillo y breve por el cual la justicia lo ampare contra actos de la autoridad que violen, en perjuicio suyo, alguno de los derechos fundamentales consagrados constitucionalmente.

En el ámbito nacional los derechos de las víctimas encuentran respaldo en varios principios y preceptos de la Constitución Política de Colombia, entre ellos, el respeto de la dignidad humana (Art. 1); el deber de las autoridades de proteger los bienes jurídicos de todas las personas residentes en Colombia (Art. 2); el mandato de interpretar los derechos y deberes de conformidad con los tratados y convenios internacionales que reconocen los derechos humanos (Art. 93); el reconocimiento expreso de asistencia, protección, restablecimiento del derecho y reparación integral (Art. 250 núm. 6 y 7). Este breve repaso da cuenta de la naturaleza interdependiente ${ }^{9}$ y complementaria de los derechos de las víctimas, en la medida en que el disfrute de un derecho depende para su existencia de la realización de otro derecho o de un grupo de derechos.

Por su lado, la Ley 906 de 2004 se refiere a los derechos de las víctimas en su Art. 11, el cual alude en primer término a la obligación del Estado de garantizar el acceso a la administración de justicia ${ }^{10}$. En desarrollo de ese mandato, las víctimas tienen derecho a: recibir durante todo el procedimiento, un trato humano y digno (a); a la protección de su intimidad, a la garantía de su seguridad, a la de sus familiares y testigos a favor (b); a una pronta e integral reparación de los daños sufridos a cargo del autor o partícipe del injusto o de los terceros llamados a responder en los términos de este código (c); a ser oídas y a que se les facilite el aporte de pruebas (d); a recibir desde el primer contacto con las autoridades y en los términos establecidos en este código, información pertinente para la protección de sus intereses y a conocer la verdad de los hechos que conforman las circunstancias del injusto del cual han sido

9 La Declaración y Programa de Acción de Viena de 1993 caracteriza todos los derechos humanos como universales, indivisibles interdependientes y relacionados entre sí.

10 En la Sentencia C-454 de 2006 ya citada, la Corte Constitucional puntualiza que "la efectividad del derecho a acceder a la justicia, en el que se inscriben los derechos a la verdad, a la justicia y a la reparación de las víctimas, se encuentra en una relación directa con el derecho a probar. El derecho a conocer la verdad sobre los hechos que entrañan el agravio a la víctima, está inescindiblemente vinculado con la posibilidad de probar; el derecho a la justicia resulta inconcebible al margen de una posibilidad real de incidir probatoriamente en el esclarecimiento de los hechos y la determinación de responsabilidades; y el derecho a la reparación, cuando se ejerce en el proceso penal, se consolida a partir de la determinación de la responsabilidad por el hecho punible". 
víctimas (e); a que se consideren sus intereses al adoptar una decisión discrecional sobre el ejercicio de la persecución del injusto (f); a ser informadas sobre la decisión definitiva relativa a la persecución penal; a acudir, en lo pertinente, ante el juez de control de garantías y a interponer los recursos ante el juez de conocimiento cuando a ello hubiere lugar (g); a ser asistidas durante el juicio y el incidente de reparación integral por un abogado que podrá ser designado de oficio (h); a recibir asistencia integral para su recuperación en los términos que señale la ley (i); a ser asistidas gratuitamente por un traductor o intérprete en el evento de no conocer el idioma oficial, o de no poder percibir el lenguaje por los órganos de los sentidos (j).

Lo concerniente a la intervención procesal de las víctimas, también es materia de regulación en el Art. 137 de la ley 906 de 2004, bajo el entendido que tienen el derecho a hacerlo en todas las fases de la actuación penal, de acuerdo con unas reglas determinadas. Sin embargo, parece no guardar armonía la premisa anterior con las pautas que fija el mismo texto normativo, pues de cierta forma se limitan sus derechos por las razones expuestas en apartados anteriores.

En relación con esta temática, la jurisprudencia constitucional ha reiterado quela formalización de la intervención de la víctima se produce en la audiencia de formulación de acusación, momento procesal en que así mismo se define la condición de acusado y se traba de manera formal el contradictorio entre acusación y defensa. El hecho de que sea en ese estadio de la actuación en el que se determina la calidad de víctima a fin de legitimar su intervención en el juicio y se reconozca su representación legal, si la tuviere, de ninguna manera significa su exclusión de etapas anteriores en las que bien puede intervenir acreditando sumariamente su condición de tal, como lo prevé el artículo 136 y lo ha reafirmado y precisado la jurisprudencia de esta Corte (C- 516/2007, M.P.: Jaime Córdoba Triviño).

Según lo dispone el Art. 137 numeral 3 de la mencionada ley, no es obligatorio que para el ejercicio de sus derechos las víctimas estén representadas por un abogado, sin embargo, a partir de la audiencia preparatoria y para intervenir tendrán que ser asistidas por un profesional del derecho o estudiante de consultorio jurídico de Facultad de Derecho debidamente aprobada. Cabe preguntarse ahora: ¿Se encuentran debidamente informadas las víctimas en Colombia, a fin de lograr una intervención procesal para el goce efectivo de sus derechos, sin necesidad de la asistencia legal de un abogado en las etapas anteriores a la audiencia preparatoria?

La respuesta a este interrogante guarda relación estrecha con la garantía del derecho de acceso a la justicia prevista en el Art. 229 de la Constitución. De allí nace el deber inexcusable de las autoridades que intervienen en la fase de indagación e investigación, de comunicar a las víctimas sobre sus derechos, extendiéndose incluso a las facultades procesales que se derivan de los derechos a la verdad y a la justicia. Respecto de esta garantía que cobija a las víctimas, la Corte Constitucional en la Sentencia C-454 de 2006 (M.P.: Jaime Córdoba Triviño), considera que: 
La interconexión e interdependencia que existe entre los derechos a la verdad, a la justicia, y a la reparación exige que la garantía de comunicación se satisfaga desde el primer momento en que las víctimas entran en contacto con los órganos de investigación. Los derechos a la justicia y a la reparación pueden verse menguados si se obstruye a la víctima las posibilidades de acceso a la información desde el comienzo de la investigación a efecto de que puedan contribuir activamente con el aporte de pruebas e información relevante sobre los hechos.

\section{SITUACIÓN DE LOS DERECHOS DE LAS MUJERES VÍCTIMAS DE VIOLENCIA SEXUAL}

La violencia contra la mujer constituye un acto de discriminación fundado en la pertenencia al sexo femenino, pues como lo afirma Carmona (2010) "la desigualdad de poder inherente al desempeño de los roles de género así como la manera estereotipada de asumir el género femenino y el masculino, resultan significativos a la hora de hablar de violencia de género" (p. 11).

A nivel internacional, como respuesta a los movimientos sociales de mujeres, la Declaración de Naciones Unidas sobre la Eliminación de la Violencia contra la Mujer (1993) además de afirmar que es un acto violatorio de derechos humanos, la reconoce como manifestación de relaciones de poder históricamente desiguales entre el hombre y la mujer, que han conducido a su dominación y discriminación. Este instrumento declarativo se ocupa de definir la violencia contra la mujer en su Artículo 1, como todo acto de violencia basado en la pertenencia al sexo femenino que tenga o pueda tener como resultado un daño o sufrimiento físico, sexual o sicológico para la mujer, así como las amenazas de tales actos, la coacción o la privación arbitraria de la libertad, tanto si se producen en la vida pública como en la vida privada.

En relación con el derecho de acceso a la justicia y dada la necesidad de proteger especialmente a las víctimas en situación de vulnerabilidad, La Cumbre Judicial Iberoamericana (2008) consideran en esa condición a "aquellas personas que, por razón de su edad, género, estado físico o mental, o por circunstancias sociales, económicas, étnicas o culturales, encuentran especiales dificultades para ejercitar con plenitud ante el sistema de justicia los derechos reconocidos por el ordenamiento jurídico" [Regla (3)]. Asimismo, afirman como uno de los obstáculos para el acceso a la justicia "la discriminación que sufre la mujer en determinados ámbitos" [Regla (17)] y destacan que "la vulnerabilidad de la víctima puede tener su origen, tanto en las propias características personales, como en las circunstancias de la infracción penal, fenómeno que incluye a las víctimas de delitos sexuales" [Regla (11)].

Otro aspecto que no puede pasar desapercibido en cuanto incide negativamente en los derechos de las mujeres víctimas de delitos sexuales, consiste en su 
revictimización al momento de denunciar los hechos ante el sistema de justicia penal, pues al igual que sucede en otros escenarios de la vida social, los operadores judiciales y los organismos de carácter administrativo y logístico que prestan apoyo a los funcionarios del sistema, reproducen estereotipos de género como el de "víctima culpable" y muchos otros que acentúan la discriminación contra las mujeres y la violación de sus derechos.

En este sentido, el informe temático de Amnistía Internacional (2011), acerca de la violencia sexual contra mujeres en el conflicto armado en Colombia, pone de manifiesto la gravedad de la discriminación, cuando refiere que:

Las actitudes sociales que culpan a las mujeres y a las niñas en lugar de al [sic] autor de los abusos tienen como efecto silenciar a las sobrevivientes y a sus familias. La arraigada discriminación de género es la causa primordial de que, para empezar, el Estado no dé protección a las mujeres, y no haga responder ante la justicia a los responsables de la violencia contra ellas. Toda la violencia sexual en Colombia, y en otros países, se alimenta de una aceptación general en la sociedad de que es una parte normal de la vida de las mujeres y las niñas, y no un comportamiento criminal aberrante (p. 5).

Del mismo modo, Bovino (1997) expresa:

A estas circunstancias se debe agregar el proceso de revictimización que tiene lugar cuando la justicia penal se hace cargo del caso, que se caracteriza por cuestionar a la propia víctima por su participación en el conflicto, es decir, en la revictimización de aquellas mujeres que deciden acudir a la justicia penal y en el carácter manifiestamente sexista de las prácticas de este tipo de justicia (p.135).

Sobre este particular, la Comisión Interamericana de Derechos Humanos en su informe temático sobre "Acceso a la Justicia para Mujeres Víctimas de Violencia en las Américas", destaca la situación desfavorable que para las mujeres comportan las visiones basadas en estereotipos de género cuando manifiesta que:

La influencia de patrones socioculturales discriminatorios puede dar como resultado una descalificación de la credibilidad de la víctima durante el proceso penal en casos de violencia y una asunción tácita de responsabilidad de ella por los hechos, ya sea por su forma de vestir, por su ocupación laboral, conducta sexual, relación o parentesco con el agresor, lo cual se traduce en inacción por parte de los fiscales, policías y jueces ante denuncias de hechos violentos. Esta influencia también puede afectar en forma negativa la investigación de los casos y la valoración de la prueba subsiguiente, que puede verse marcada por nociones estereotipadas sobre cuál debe ser el comportamiento de las mujeres en sus relaciones interpersonales (2007, párr. 155). 
En orientación semejante, la Corte Interamericana de Derechos Humanos en el caso Campo Algodonero vs. México, se pronunció así:

El estereotipo de género se refiere a una pre-concepción de atributos o características poseídas o papeles que son o deberían ser ejecutados por hombres y mujeres respectivamente [...] La creación y uso de estereotipos se convierte en una de las causas y consecuencias de la violencia de género en contra de la mujer (2009, párr. 401).

El panorama referido desvela además, la incontestable violación de los derechos humanos, según se ha reconocido en distintos instrumentos internacionales ${ }^{11}$. Desde este punto de vista, los movimientos sociales de mujeres a nivel mundial, han llamado la atención de los Estados y de organismos no gubernamentales, a fin otorgar la entidad política al problema y promover la adopción de políticas públicas que apunten a la eliminación de toda forma de violencia y discriminación contra la mujer.

\section{ANÁLISIS DE LA DINÁMICA PROCESAL EN LA INVESTIGACIÓN DE DELITOS SEXUALES EN LAS FISCALÍAS DE BUCARAMANGA}

Como se planteó al inicio de este artículo de reflexión, el análisis de los derechos de las víctimas se complementa con varios de los hallazgos que forman parte de la investigación referenciada. En ese contexto, se observan tres dinámicas procesales en el período 2007-2010 ${ }^{12}$ que afectan de manera negativa el derecho de acceso a la administración de justicia de las mujeres víctimas de delitos sexuales: en primer lugar, el elevado número de procesos en la fase de indagación, 45 de 51 casos activos, cifra significativa especialmente en los años 2007 y 2008, puesto que se hallaron diligencias sin formulación de imputación pasados casi 4 años. En segundo lugar, una cifra alta de archivos, con 135 casos sobre 210 denuncias, y por último, el que tan solo tres procesos obtuvieran sentencia, como se muestra en la Tabla 1.

11 Entre los instrumentos internacionales pertinentes se destacan: La Convención sobre la Eliminación de todas las formas de Discriminación contra la Mujer (CEDAW), punto de partida para la visibilizacion de la problemática que aqueja a las mujeres. De igual forma, la Declaración sobre la Eliminación de la Violencia contra la Mujer, en la medida que considera este tipo de violencia como una manifestación de las relaciones de poder desiguales entre hombres y mujeres, la Convención Interamericana para Prevenir, Sancionar y Erradicar la Violencia contra la Mujer (Convención de Belém Do Pará), la cual reconoce el derecho de la mujer a vivir libre de violencias.

12 Los datos en esta materia, proceden del archivo electrónico de la Fiscalía Segunda Seccional Unidad de Delitos Sexuales del Centro de Atención Integral a Víctimas de Abuso Sexual-CAIVAS, Bucaramanga, el cual se seleccionó como muestra, bajo la autorización de la Fiscal Coordinadora. 
Tabla 1. Dinámica procesal en la Fiscalía Segunda Seccional CAIVAS-Bucaramanga

\begin{tabular}{cccccc}
\hline AÑO & DENUNCIAS & ARCHIVO & $\begin{array}{c}\text { Cambio de } \\
\text { competencia } \\
\text { Ley } \mathbf{6 0 0}\end{array}$ & $\begin{array}{c}\text { Cambio de } \\
\text { competencia } \\
\text { fuera de la FGN }\end{array}$ & $\begin{array}{c}\text { Procesos } \\
\text { con } \\
\text { Sentencia }\end{array}$ \\
\hline 2007 & 51 & 35 & 0 & 10 & 2 \\
2008 & 53 & 34 & 0 & 4 & 1 \\
2009 & 56 & 41 & 0 & 2 & 0 \\
2010 & 50 & 25 & 2 & 3 & 0 \\
TOTAL & $\mathbf{2 1 0}$ & $\mathbf{1 3 5}$ & $\mathbf{2}$ & $\mathbf{1 9}$ & $\mathbf{3}$ \\
\hline
\end{tabular}

Fuente: Elaboración del equipo de investigación a partir de la base de datos de la Fiscalía Segunda Seccional del CAIVAS-Bucaramanga.

\subsection{Procesos en indagación}

Llama la atención durante el período en análisis el alto porcentaje de procesos en indagación (más del 70\% de los procesos activos), debido a que no constituye beneficio alguno para las partes e intervinientes, menos aún para la víctima, pues el hecho de que un proceso lleve hasta 4 años sin realizarse siquiera la formulación de imputación, deja entrever una tendencia a la impunidad, fenómeno incompatible con el deber de actuar que tiene el Estado para prevenir, investigar y sancionar la violencia contra la mujer, según lo dispone el Art. 7a. de la Convención de Belém do Pará.

Conviene aclarar que en desarrollo de la etapa de recolección de la información, no se tuvo acceso a las carpetas que manejan los fiscales en cada caso. De allí que no se haya logrado la determinación de las causas atribuibles con tan elevado porcentaje de procesos en indagación. No obstante, el solo dato estadístico presentado, muestra el efecto desfavorable que sobre los derechos de las víctimas genera esta congestión judicial, por no guardar armonía con lo previsto en los tratados internacionales, entre ellos, el Artículo 8 de la Declaración Universal de los Derechos Humanos; el Artículo 2-3 del Pacto Internacional de Derechos Civiles y Políticos; el Artículo XVIII de la Declaración Americana de los Derechos y Deberes del Hombre; los Artículos 5 y 6 de la Convención sobre la Eliminación de todas las Formas de Discriminación contra la Mujer-CEDAW que estatuyen el deber de los Estados de garantizar el derecho de acceso a la justicia.

\subsection{Archivo de diligencias}

Es preciso resaltar, cómo en la fase de indagación la Fiscalía tiene la facultad de disponer el archivo de la actuación, ante la inexistencia de motivos o circunstancias de orden fáctico que permitan su configuración como delito, o indiquen su posible existencia como tal, de conformidad con lo dispuesto en el Art. 79 de la Ley 906 de 2004. 
En esta materia, se encontró que es significativo el número de actuaciones archivadas si se analiza comparativamente con el número de denuncias interpuestas por los delitos en estudio: de 210 denuncias, 135 fueron objeto de archivo. Incluso estos datos no se apartan de los resultados obtenidos por un estudio llevado a cabo por la Corporación Excelencia en la Justicia, en el cual para el año 2011:

La mayoría de los procesos evacuados en dicho año por la Fiscalía, (...) corresponden al archivo de las diligencias de indagación, forma de terminación que fue aplicada a 4.298 noticias criminales. En cuanto a la causal del archivo, llama la atención que en un $46 \%$ de los casos en que se aplicó esta salida se invocó la atipicidad de la conducta (es decir, por no tratarse de conductas proscritas bajo el Código Penal), mientras que otro $24 \%$ de estas noticias criminales fueron archivadas por inexistencia del hecho (2013, párr.3).

Dado que la decisión de archivo afecta directamente a las víctimas, reviste importancia la necesidad de evaluar las falencias en las labores de investigación, con miras a la adopción de mecanismos tendientes a la efectiva garantía del derecho a la verdad de que son titulares las víctimas del delito en general, y de manera particular, las mujeres víctimas de violencia sexual, como quiera que les asiste el interés legítimo de que se adelante una investigación previa con miras a conocer la verdad, y de paso, evitar la impunidad, en el marco de una descongestión judicial razonada.

En relación con las órdenes de archivo de diligencias, es de destacar la obligatoriedad de dar comunicación de ello a las víctimas, en tanto tienen derecho a aportar nuevos elementos materiales probatorios que permitan la reapertura de la investigación, en donde, al llegar a existir controversia con la Fiscalía sobre la reanudación de la investigación, cabe acudir ante el Juez de Control de Garantías, como lo ha señalado la Corte Constitucional (Sentencia C-1154/ 2005. M.P.: Manuel J, Cepeda).

Por la especial trascendencia del archivo se hace indispensable la participación activa de las víctimas, quienes han de estar asesoradas, conocer sus derechos y contar con el acompañamiento de un representante o apoderado que vele por sus intereses. Sólo en esta perspectiva puede afirmarse la existencia de un control efectivo sobre la decisión bajo análisis y además se reitera cómo el carácter obligatorio de la representación de víctimas por un abogado a lo largo de todo el proceso, se constituye en factor primordial para la garantía de los derechos a la verdad, la justicia y la reparación.

En el siguiente apartado adquiere importancia para los fines de este análisis, establecer el tiempo transcurrido entre la ocurrencia de los hechos, la denuncia y la asignación de fiscal, por cuanto inciden en el curso del caso, incluso pueden dar lugar a la decisión de archivo. 
Tabla 2. Tiempo transcurrido entre la ocurrencia de los hechos, la recepción de la denuncia y la asignación de fiscal

\begin{tabular}{ccccccccccc}
\hline RANGO & \multicolumn{4}{c}{ HECHOS - DENUNCIA } & \multicolumn{5}{c}{ DENUNCIA - ASIGNACIÓN } \\
DE DÍAS & 2007 & 2008 & 2009 & 2010 & Total & 2007 & 2008 & 2009 & 2010 & Total \\
\hline Por & 8 & 3 & 0 & 1 & $\mathbf{1 2}$ & 0 & 0 & 0 & 0 & $\mathbf{0}$ \\
establecer & & & & & & & & & & \\
$0-5$ & 75 & 101 & 103 & 89 & $\mathbf{3 6 8}$ & 114 & 93 & 93 & 85 & $\mathbf{3 8 5}$ \\
$6-10$ & 12 & 6 & 10 & 11 & $\mathbf{3 9}$ & 3 & 20 & 25 & 25 & $\mathbf{7 3}$ \\
$11-15$ & 5 & 4 & 3 & 3 & $\mathbf{1 5}$ & 5 & 8 & 10 & 14 & $\mathbf{3 7}$ \\
$16-20$ & 1 & 6 & 0 & 4 & $\mathbf{1 1}$ & 1 & 3 & 3 & 2 & $\mathbf{9}$ \\
$21-25$ & 1 & 2 & 2 & 2 & $\mathbf{7}$ & 0 & 5 & 2 & 1 & $\mathbf{8}$ \\
$26-30$ & 1 & 5 & 2 & 3 & $\mathbf{1 1}$ & 0 & 2 & 3 & 2 & 7 \\
Más de 30 & 22 & 18 & 26 & 18 & $\mathbf{8 4}$ & 3 & 15 & 12 & 5 & $\mathbf{3 5}$ \\
Más de 365 & 1 & 4 & 5 & 3 & $\mathbf{1 3}$ & 0 & 3 & 3 & 0 & $\mathbf{6}$ \\
TOTAL & $\mathbf{1 2 6}$ & $\mathbf{1 4 9}$ & $\mathbf{1 5 1}$ & $\mathbf{1 3 4}$ & $\mathbf{5 6 0}$ & $\mathbf{1 2 6}$ & $\mathbf{1 4 9}$ & $\mathbf{1 5 1}$ & $\mathbf{1 3 4}$ & $\mathbf{5 6 0}$ \\
\hline
\end{tabular}

Fuente: Elaboración del equipo de investigación sobre la base de datos de las Fiscalías Primera, Segunda y Tercera Seccionales del CAIVAS-Bucaramanga.

Con apoyo en la información recolectada, clasificada y organizada que trajo consigo la elaboración de la Tabla 2, es posible hacer un análisis del tiempo transcurrido entre la ocurrencia de los hechos, su denuncia y posterior asignación por reparto a un fiscal. Así, entre los años 2007 y 2010 se instauraron 368 denuncias dentro de los 5 días posteriores a los hechos; 84 fueron interpuestas más allá de un mes de la ocurrencia del suceso y 39 se dieron a conocer a las autoridades en un lapso superior a un año.

Lo anterior demuestra que gran parte de los casos de violencia sexual se denunciaron relativamente de manera oportuna ${ }^{13}$ (368 casos en el rango de 0 a 5 días), empero 180 denuncias se formularon -entre 6 y más de 365 días- cifra considerable que muestra de manera global que los hechos se dieron a conocer a las autoridades de manera tardía, y por ello resulta difícil para la Fiscalía la obtención de evidencia física, o definitivamente se enfrenta a la imposibilidad de levantarla por haber desaparecido, si se tiene en cuenta el largo tiempo transcurrido. Todo ello aunado a que los recuerdos son cada vez más borrosos en la mente de las víctimas. El fenómeno explicado da lugar a una decisión de archivo, por la ausencia de evidencia física y elementos materiales probatorios.

13 Lo ideal sería que las mujeres denunciaran los hechos de violencia sexual inmediatamente después de su ocurrencia. 
Uno de los varios interrogantes que surge alrededor del problema puesto en evidencia, consiste en establecer cuál es el motivo por el cual las mujeres siguen denunciando tardíamente los hechos de violencia sexual. Sobre este asunto ha de decirse que puede ser atribuible al temor a denunciar por parte de la víctima, a la falta de conocimiento de sus derechos, a la tácita aceptación de la violencia como algo normal, o a la desconfianza en el sistema de justicia, entre otros. En esta línea, el Informe Mundial sobre la Violencia y la Salud (OMS, 2003) da cuenta de que "muchas mujeres no denuncian a las autoridades los hechos, por vergüenza, por temor a que se les culpe de la situación, no se les crea o se les someta a otro tipo de vejaciones" (p. 163).

A estas circunstancias, la Corporación Humanas (2008) añade el desconocimiento de los derechos por parte de la mujer que no reconoce haber sido víctima de delito alguno, posición que en muchos casos comparte también el victimario y los operadores de justicia, y que es producto de la discriminación género subyacente a un orden social desigual basado en una jerarquización de género. Incluso, el mismo sistema penal no reconoce estos factores, ni el hecho de que la violencia no es más que el resultado de unos patrones sociales ampliamente aceptados, que como lo demuestra un sinnúmero de estudios (Gutiérrez, 2008, 34-48), discriminan a la mujer, impiden su autonomía y empoderamiento dentro de la sociedad.

En lo que concierne al tiempo transcurrido desde la recepción de la denuncia hasta la asignación a un fiscal, entre los años 2007 a 2010, de 560 casos en 385 de ellos el trámite demoró menos de 5 días; en 73 menos de 10 días y en 37 de 11 a 15 días. Es de tener en cuenta que en 35 de los hechos denunciados, la asignación de fiscal tardó más de 30 días, y en 6 , más de un año. En desarrollo del proyecto de investigación no fue posible concretar la causa de esta demora, lo único cierto es que afecta de modo negativo el curso del caso, por implicar una dilación en los procesos en menoscabo del acceso efectivo a la justicia. Asimismo, se opone a las recomendaciones realizadas por la Comisión Interamericana de Derechos Humanos (2007) dirigidas a "garantizar la debida diligencia para que todos los casos de violencia de género sean objeto de investigación inmediata, completa e imparcial que redunde en la condena de los perpetradores y en la reparación de la víctima" (p. 21). Del mismo modo, la Comisión expresa que "cuando las autoridades no están capacitadas en materia de género, y no colaboran entre sí, se generan retrasos y vacíos clave en las investigaciones, los que afectan negativamente el futuro procesal del caso" (p. 22).

\section{CONCLUSIONES}

Dada la dificultad de acceso a la información oficial sobre delitos sexuales, debido a factores como la falta de unificación en la sistematización de los datos por los sistemas de trabajo en las fiscalías, la ausencia de indicadores de género, y la escasa disposición de los operadores de justicia en facilitar la información solicitada con fines investigativos, se requiere fortalecer los programas de formación orientados al conocimiento y a la sensibilización sobre asuntos de género. 
Como la participación de la víctima dentro de la actuación penal bajo la ley 906 de 2004 se ve limitada por no tener el carácter de parte, sino de interviniente especial, razón por la cual no se halla en igualdad de condiciones si se compara con el acusado, quien sí tiene garantizado su derecho a contar con la asistencia legal de un abogado que procure su defensa técnica a lo largo de todo el proceso penal, se hace necesario establecer por vía legislativa la obligatoriedad de designar un abogado desde el inicio de la actuación penal, a fin de garantizar la realización efectiva de los derechos de las víctimas.

Si se tiene en cuenta que el elevado porcentaje de diligencias en indagación contraviene lo dispuesto en los instrumentos internacionales que exigen celeridad y eficacia en los procedimientos en los casos de violencia sexual contra las mujeres, es importante permitir a las organizaciones sociales de mujeres, el acompañamiento a las víctimas como un mecanismo de control y de participación ciudadana en las actuaciones judiciales que las afectan. En este sentido, los resultados de la investigación permitieron corroborar la existencia de una relación directa entre la debida diligencia y celeridad en los procesos penales y el acceso a la justicia.

La elevada cifra de diligencias archivadas es un fenómeno que involucra tanto a la Fiscalía, por su escasa capacidad técnica para esclarecer los hechos, como a las víctimas, por el desconocimiento de sus derechos. Por ello, es urgente aumentar el porcentaje del presupuesto nacional destinado al cabal cumplimiento de las funciones de investigación, en el cual se reserve un rubro que garantice la asistencia legal de las víctimas.

Es evidente que la falta de efectividad del sistema de justicia penal, en lo concerniente a la investigación de los hechos de violencia sexual contra las mujeres y a la sanción de sus perpetradores, propicia la impunidad y la consiguiente violación de derechos. En este aspecto se recomienda realizar programas educativos de carácter masivo, con el apoyo de los medios de comunicación, de organizaciones de derechos humanos, que impidan silenciar la gravedad de la problemática de discriminación y violencia contra la mujer.

\section{REFERENCIAS}

Amnistía Internacional. (2011). Eso es lo que nosotras exigimos que se haga justicia. Impunidad por actos de violencia sexual cometidos contra las mujeres en el conflicto armado en Colombia, Madrid: Editorial Amnistía Internacional. Recuperado en septiembre 22, 2012, disponible en: http://www.amnesty.org/es/ stay-informed/publications/books/Colombia-Que-se-haga-justicia

Bovino, A. (1997). Delitos sexuales y feminismo legal: [algunas] mujeres al borde de un ataque de nervios. Revista Jurídica de la Universidad de Palermo. (1) y (2), 133-148. Recuperado en julio 18, 2011, disponible en: http://www.palermo. edu/derecho/publicaciones/pdfs/revista_juridica/n2N1y2-Abril1997/02\%20 1y2Juridica07.pdf 
Carmona, L.S. (2010). Violencia contra la mujer en la pareja de las familias juarenses. $1^{\text {a }}$. Ed. (pp. 7-24). Universidad Autónoma de Ciudad Juárez, México D.F.: Solar Editores.

Constitución Política de Colombia. Congreso de la República. Ley 599 de 2000. Colombia. Congreso de la República. Ley 906 de 2004. Bogotá: Temis.

Corte Constitucional. Sentencia C-228 de 3 de abril de 2002. Magistrados Ponentes: Manuel José Cepeda Espinosa y Eduardo Montealegre Lynett. Colombia: No. Expediente D-3672.

Corte Constitucional. Sentencia C- 516 de 11 de julio de 2007. Magistrado Ponente: Jaime Córdoba Triviño. Colombia: No. expediente D-6554.

Corte Constitucional. Sentencia C-1154 de 15 de noviembre de 2005. Magistrado ponente Manuel José Cepeda Espinosa. No. expedientes D-5705 y D-5712 (acumulados). Colombia.

Corte Constitucional. Sentencia C-209 de 21 de marzo de 2007. Magistrado Ponente Manuel José Cepeda Espinosa. Colombia: No. expediente D-6396.

Corte Constitucional. Sentencia C-250 de 6 de abril de 2011. Magistrado Ponente Mauricio González Cuervo. Colombia: No. expedientes D-8231, D-8232, D-8240 (acumulados).

Corte Constitucional. Sentencia C-260 de 6 de abril de 2011. Magistrado Ponente Jorge Iván Palacio Palacio. Colombia: No. expediente D-8269.

Corte Constitucional. Sentencia C-454 de 7 de junio de 2006. Magistrado Ponente Jaime Córdoba Triviño. Colombia: No. expediente D-5978, corregida mediante Auto 248 de 2006.

Comisión Interamericana de Derechos Humanos. (2007). Acceso a la Justicia para las Mujeres Victimas de Violencia en las Américas, OEA/Ser.L/V/II. Doc. 68, (p. 21, pár. 155). Recuperado en abril 8, 2011, disponible en: http://www.cidh. org/women/acceso07/cap2.htm.

COMITÉ DE MINISTROS DEL CONSEJO DE EUROPA. (1985). Recomendación (85) 11, Sobre la posición de la víctima en el marco del Derecho Penal y del Proceso Penal. Recuperado en marzo 14, 2013, disponible en: http://javeriana. edu.co/juridicas/menu_lat/documents/RECOMENDACION85-11.pdf

CORPORACIÓN HUMANAS. (2008). La Situación de las Mujeres Victimas de Violencia de Género en el Sistema Penal Acusatorio, pp.40-104. Recuperado en marzo 22, 2011, disponible en: www.humanas.org.co/.../La_situacion_de_las mujeres_victimas.pdf.

CORTE INTERAMERICANA DE DERECHOS HUMANOS-IDH. (2009). Caso “Campo Algodonero" vs. México. Recuperado en febrero 2, 2012, disponible en: http://www.corteidh.or.cr/casos.cfm?idCaso=327.

De Torres Porras, F. (2010). Víctima y proceso, en La violencia de género en la ley. Reflexiones sobre veinte años de experiencia en España. 1ª. ed., Madrid, España: Dikinson, S.L. 
Gutiérrez C., G. (2008). "Violencia sexista. De la violencia simbólica a la violencia radical”, en Revista Debate Feminista. Cuerpos sufrientes, 37(19), 34-48.

Muñiz, E. (2011). El cuerpo y sus circunstancias. Una mirada cultural de la violencia sexual, en La bifurcación del caos. Reflexiones interdisciplinarias sobre la violencia falocéntrica, $1^{\mathrm{a}}$ ed., pp.85-105. México D.F: Editorial Ítaca, Universidad Autónoma Metropolitana-Xochimilco.

ORGANIZACIÓN DE LAS NACIONES UNIDAS-ONU. (2002). Oficina del Alto Comisionado de las Naciones Unidas para los Derechos Humanos, en Informe sobre la Situación de los Derechos de la Mujer en Colombia, Bogotá. Recuperado en 7 de febrero, 2010, disponible en: http://www.hchr.org.co/ documentoseinformes/informes/altocomisionado/informe2002_esp.pdf.

ORGANIZACIÓN DE LAS NACIONES UNIDAS-ONU. (1979). Convención sobre la Eliminación de todas las Formas de Discriminación contra la Mujer. Adoptada por la Asamblea General en su Resolución 34/180 de 18 de diciembre de 1979. Recuperado en marzo 11, 2011, disponible en: http:/www.un.org/ womenwatch/daw/cedaw/text/sconvention.htm

ORGANIZACIÓN DE LAS NACIONES UNIDAS - ONU. (1993). Declaración sobre la Eliminación de la Violencia contra la Mujer. Adoptada por la Asamblea General en su Resolución 48/104 del 20 de diciembre de 1993. Consultado en marzo 10, 2011, disponible en: http://www2.ohchr.org/spanish/law/pdf/mujer violencia.pdf

ORGANIZACIÓN DE LAS NACIONES UNIDAS - ONU. (1985). Declaración sobre los principios fundamentales de justicia para las víctimas de delitos y abuso de poder. Adoptada por la Asamblea General en su Resolución 40/34 de 29 de noviembre de 1985. Recuperado en marzo 24, 2011, disponible en: http:// www2.ohchr.org/spanish/law/delitos.htm

ORGANIZACIÓN DE LAS NACIONES UNIDAS - ONU. (1948). Declaración Universal de Derechos Humanos. Artículo 8. Recuperado en marzo 24, 2011, disponible en: http://www.un.org/es/documents/udhr/index_print.shtml

ORGANIZACIÓN DE LOS ESTADOS AMERICANOS - OEA. (1994). Comisión Interamericana de Derechos Humanos. Convención Interamericana para Prevenir Sancionar y Erradicar la Violencia Contra la Mujer. "Convención de Belém do Pará”, adoptada en Belém do Pará, Brasil, el 9 de junio de 1994. Recuperado en marzo 23, 2011, disponible en: http://www.cidh.org/Basicos/ Basicos8.htm

ORGANIZACIÓN DE LOS ESTADOS AMERICANOS- OEA. (1948). Declaración Americana de los Derechos y Deberes del Hombre, adoptada en la Novena Conferencia Internacional Americana. Artículo XV. Recuperado en julio 15, 2011, disponible en: http://www.oas.org/es/cidh/mandato/Basicos/declaracion. asp 
ORGANIZACIÓN MUNDIAL DE LA SALUD- OMS. (2003). Informe Mundial sobre la Violencia y la Salud. Capítulo 6: Violencia sexual. Recuperado en junio 14, 2011, disponible en: http://www.who.int/violence_injury_prevention/ violence/world_report/es/index.html

Patiño, M.C. (2009). La intervención procesal de la víctima: Especial consideración a los sistemas procesales de la Ley 906/04, 975/05, Sistema Interamericano de Derechos Humanos y Corte Penal Internacional. $1^{a}$ ed., Bogotá, Colombia: Universidad Nacional de Colombia. Facultad de Derecho y Ciencias Políticas y Sociales.

Secretaria General del Senado de la República. Antecedentes de Acto Legislativo. Recuperado en octubre 10, 2011, disponible en: http://secretariasenado.gov.co

Pitch, T. (2003). Un derecho para dos. La construcción jurídica de género, sexo y sexualidad. Madrid, España: Editorial Trotta.

Torras, M. (2007). El delito del cuerpo. De la evidencia del cuerpo al cuerpo en evidencia, en Cuerpo e identidad I. Barcelona: Ediciones UAB, 11-36. Recuperado en febrero 12, 2013, disponible en: http:/cositextualitat.uab.cat/ web/wp-content/uploads/2011/03/Meri-Torras_Cuerpo_e_identidad.pdf.

XIV CUMBRE JUDICIAL IBEROAMERICANA. (2008). Reglas de Brasilia sobre Acceso a la Justicia de las Personas en condición de Vulnerabilidad. Brasilia, 4 a 6 de marzo de 2008. Recuperado en mayo 9, 2011, disponible en: http://www. cumbrejudicial.org/c/document_library 